\title{
Genetic Characteristics of Multiparous Goats according to the Loci of Some Polymorphous Proteins in Blood and Milk
}

\author{
M.V. Badalyan, Yu.G. Marmaryan, D.S. Navasardyan \\ Armenian National Agrarian University \\ S.A. Kharatyan \\ "Scientific Center for Risks Assessment and Analysis in Food Safety Area" SNCO of RA \\ badalyan.manvel@mail.ru, yu.marmaryan@anau.am, davitnav@gmail.com, satenik.kharatyan@mail.ru
}

\section{A RT I CLE IN F O}

\section{Keywords:}

goat,

genotype,

allele,

locus,

polymorphous protein

\begin{abstract}
A B S T RA C T
The issues related to the study of multiparity in agricultural animals as a prior biological property, and those to making it more manageable were raised in the scientific research field still at the beginning of previous century. To solve the mentioned issues multiple approaches and hypotheses were drawn forward in different periods, but they were very often mutually exclusive. The article considers the genetic characteristic of multiparous goats per the loci of some polymorphous proteins in the blood and milk with the aim of applying the detected genetic markers in the selection process of the branch.
\end{abstract}

\section{Introduction}

The high productivity of agricultural animals is the most significant component of animal husbandry; that is why the vector of all contemporary technologies is directed to the highly efficient use of animals' bio-economic properties, metabolism and biosynthesis.

Multiparity, as an important bio-economic property, has always been within the scope of interest of animal breeders and selectionists, and multiple investigations have been conducted in that direction. Nevertheless, not always was it possible to make it efficient and manageable, since there are still mutually exclusive opinions regarding the heredity coefficient of multiparity and nature of inheritance recorded in the professional literature sources (Lotokov, 1935, Davydov, 1936).

The use of molecular genetics and biotechnological methods in animal husbandry has enabled to consider some matters from other standpoints (Shen, et al., 2004).

It should be mentioned that such type of research works are hardly or scarcely found in the sources of professional literature, whereas, in Armenia, they are conducted for the first time. 


\section{Materials and methods}

The experimental studies were conducted based on the investigations of blood and milk electrophoresis in 27 multiparous goats bred in Akhlatyan, Tolors and Brnakot communities of the Syunik region in 2020, while in 2019, they were implemented based on the same investigations in 6 multiparous goats bred in the Krashen goat breeding farm in the Shirak region.

The blood serum and homolysis have been studied through the accepted methods: in the blood serum the loci of transferrin $(\mathrm{Tf})$, ceruloplasmin $(\mathrm{Cp})$ and hemoglobin $(\mathrm{Hb})$ (Badalyan, et al., 2018) and in milk the loci of $\alpha$-lactalbumin (La), $\beta$ - lactoglobulin ( $\mathrm{Lg}), \alpha \mathrm{S} 1$ casein $(\alpha \mathrm{S} 1-\mathrm{Cn}), \beta$ casein $(\beta-\mathrm{Cn})$ have been examined (Albenzio, et al., 2009, Rout, et al., 2010, Sulimova, et al., 2007).

The investigations were carried out in the laboratory of Serology and Molecular Biology at "Scientific Center for Risks Assessment and Analysis in Food Safety Area" SNCO.

Electrophoresis was performed on $10 \%$ polyacrylamide gel in case of blood serum proteins; while in case of milk proteins it was done on $13 \%$ polyacrylamide gel (Osterman, 1981).

After electrophoresis, the gel was fixed in the solution for 60 minutes, after which it was painted with Kumas G250 paint for 30-60 minutes, then washed 3 times with $10 \%$ acetic acid solution (washing buffer) (Schagger\&Jagow, 1987).

The results of foregram have been analyzed through the corresponding formulae. The frequency of genotypes and alleles has been determined through the following formula:

$$
P_{i}=\frac{n_{i}}{N}
$$

where $P_{i}$ is the frequency of $\mathrm{i}$ allele, $n_{i}$ is the number of animals carrying the given allele, $N$ is the total number of investigated animals.

The percentage of genotypes homozygosity for each locus has been determined through the principle of regular proportion of the total animal number under study.

The degree of homozygosity in the indicators of immunogenetic parameters of the gene pool of the population or the investigated group has been determined through the Helderman's formula (Merkureva, 1991):

$$
S H=\sqrt{\frac{\sum\left(H_{1}-H\right)^{2}}{n},}
$$

where $\mathrm{SH}$ is the homozygosity coefficient with several loci, $H_{1}$ is the degree of homozygosity in each locus, $n$ is the quantity of investigated loci.

\section{Results and discussions}

The analysis of electrophoresis results (Table 1) for the blood polymorphic proteins ( $\mathrm{Tf}, \mathrm{Cp}, \mathrm{Hb}$ ) reveals that the transferrin locus in goats is polymorphic composed of TfA, TfC and TfD alleles, the frequency of which equals to $0.18,0.19$ and 0.63 respectively; TfA allele is manifested via 2 genotypes - TfAB (0.33) and TfAC (0.18). TfC allele has formed TfCC homozygous genotype, the occurrence rate of which is equal to $11 \%$. As to TfD allele, it is also manifested via one homozygous TfDD genotype with 0.38 occurrence rate. The homozygosity degree of transferrin locus makes $50 \%$.

\begin{tabular}{|c|c|c|c|c|c|c|c|c|c|c|c|c|c|}
\hline \multirow{3}{*}{ Locus } & \multirow{3}{*}{ n } & \multicolumn{10}{|c|}{ Frequency $P_{i}$} & \multirow{2}{*}{\multicolumn{2}{|c|}{ Homozygosity degree }} \\
\hline & & \multicolumn{7}{|c|}{ Genotypes, \% } & \multicolumn{3}{|c|}{ Alleles } & & \\
\hline & & $\mathbf{A B}$ & $\mathbf{A C}$ & AD & $\mathrm{CC}$ & CD & DD & DF & A & C & D & $\begin{array}{l}\text { According to } \\
\text { Tf, Cp, Hb loci }\end{array}$ & $\begin{array}{l}\text { According to } \\
\text { individual loci }\end{array}$ \\
\hline $\mathrm{Tf} /$ transferrin/ & 27 & 0.33 & 0.18 & - & 0.11 & - & 0.38 & - & 0.18 & 0.19 & 0.63 & & 50 \\
\hline Cp /ceruloplasmin/ & 27 & 0.13 & 0.10 & 0.13 & - & 0.24 & 0.40 & - & 0.21 & 0.38 & 0.41 & 37 & 20 \\
\hline $\mathrm{Hb} /$ hemoglobin/ & 27 & - & 0.24 & 0.38 & 0.12 & 0.10 & 0.16 & - & 0.41 & 0.25 & 0.34 & & 40 \\
\hline
\end{tabular}

Table 1. Genetic structure of multiparous goats according to $\mathrm{Tf}, \mathrm{Cp}$ and $\mathrm{Hb}$ loci* 
The locus of ceruloplasmin, as well as the previous one, is polymorphic composed of $\mathrm{CpA}, \mathrm{CpC}$ and $\mathrm{CpD}$ alleles, the occurrence rate of which is equal to $0.21,0.38$ and 0.41 respectively. The ceruloplasmin allele $\mathrm{CpA}$ has been manifested through 3 heterozygous genotypes CpAB (0.13), CpAC (0.10) and CpAD (0.13). The CpC allele of the same locus has come forth through $\mathrm{CpCD}$ heterozygous genotype, the occurrence rate of which is equal to 0.24 . Regarding the $\mathrm{CpD}$ allele, it is worth mentioning that it has been manifested in the cytoplasmic locus via 1 homozygous genotype $\mathrm{CpDD}$, the occurrence rate of which is equal to 0.40 . The degree of homozygosity in ceruloplasmin locus is equal to $20 \%$.

The hemoglobin locus is also polymorphic composed of $\mathrm{HbA}, \mathrm{HbC}, \mathrm{HbD}$ alleles, the occurrence rate of which is $0.41,0.25,0.34$ respectively; $\mathrm{HbA}$ allele has been manifested via two heterozygous genotypes - HbAC and $\mathrm{HbAD}$, the occurrence rate of which makes 0.24 and 0.38 respectively. The $\mathrm{HbC}$ allele of hemoglobin locus has come forth via 2 genotypes ( $\mathrm{HbCC}(0.12)$ homozygous and $\mathrm{HbCD}(0.16)$ heterozygous). As to $\mathrm{HbD}$ allele, it has formed only one HbDD homozygous genotype in the mentioned locus, the occurrence rate of which is $16 \%$. The degree of locus homozygosity is $40 \%$.

The degree of homozygosity in multiparous goats per the investigated loci of blood serum polymorphic proteins makes $37 \%$.

To disclose possible relations between the genetic analyses of polymorphic proteins in the goats' blood serum and their multiparity, the study results have been compared with the results of similar investigations conducted for multiparous goats of Saanen breed (Table 2).

The examined loci of transferrin, ceruloplasmin and hemoglobin in the Saanen goats were composed of A, B, D alleles, while in the local goats bred in the abovementioned communities of the Sisian province in Syunik region, they were composed of A, C, D alleles. The mentioned alleles in the Saanen goats have formed AA, AB, AC, BC, BD, $\mathrm{DD}, \mathrm{DF}$ and in the local goats $\mathrm{AB}, \mathrm{AC}, \mathrm{AD}, \mathrm{CC}, \mathrm{CD}$ and DD genotypes.

From the genetic prospect a noteworthy similarity has been recorded related to the occurrence frequency of $\mathrm{D}$ allele in the Saanen goats and local multiparous goats, which is absolutely the same.

The milk loci $\alpha$ lactalbumin (La), $\beta$ lactoglobulin (Lg), $\alpha \mathrm{S} 1$ casein $(\alpha \mathrm{S} 1-\mathrm{Cn})$ and $\beta$ casein $(\beta-\mathrm{Cn})$ have been also investigated.

The data of Table 2 indicate that $\alpha$ lactalbumin locus (La) in the milk of the local multiparous goats is polymorphic composed of $\mathrm{B}$ and $\mathrm{C}$ alleles, the frequency of which is respectively equal to 0.60 and 0.40 ; $\mathrm{B}$ allele has been manifested through two heterozygous genotypes BC (0.33) and $\mathrm{BD}(0.28)$. The $\mathrm{C}$ allele of lactalbumin has formed one heterozygous genotype $\mathrm{CF}$, the occurrence rate of which makes 0.14 . The homozygosity degree of $\alpha$ lactalbumin is equal to zero.

The locus $\beta$ lactoglobulin ( $\mathrm{Lg}$ ) is also polymorphous composed of A (0.29), C (0.31) and D (0.40) alleles. B allele has formed one heterozygous genotype $\mathrm{BC}$ with $19 \%$ occurrence frequency. As regards the $\mathrm{C}$ allele of $\beta$ lactoglobulin, it should be mentioned, that it has been manifested via 2 heterozygous genotypes CD (0.30) and $\mathrm{CF}$ (0.11). The D allele of the same locus has formed DD homozygous and DF heterozygous genotypes, the occurrence frequency of which is correspondingly equal to 0.18 and 0.22 . The homozygosity of the locus has made $20 \%$.

Regarding to $\alpha \mathrm{S} 1$ casein locus ( $\alpha \mathrm{S} 1-\mathrm{Cn})$, it should be noted, that like other loci, it is also polymorphous consisting of B (0.63), C (0.11) and D (0.26) alleles. In the mentioned case the $\mathrm{B}$ allele comes forth via two genotypes $\mathrm{BC}(0.40)$ and $\mathrm{BD}$ (0.21). The $\mathrm{C}$ allele has formed one heterozygous $\mathrm{CD}$ genotype, the occurrence rate of which makes $11 \%$.

Table 2. Genetic structure of Saanen goats per Tf, $\mathrm{Cp}$ and $\mathrm{Hb}$ loci*

\begin{tabular}{|c|c|c|c|c|c|c|c|c|c|c|c|}
\hline \multirow{3}{*}{ Locus } & \multirow{3}{*}{$\mathbf{n}$} & \multicolumn{10}{|c|}{ Frequency $P_{i}$} \\
\hline & & \multicolumn{7}{|c|}{ Genotypes, \% } & \multicolumn{3}{|c|}{ Alleles } \\
\hline & & $\mathbf{A A}$ & $\mathbf{A B}$ & $\mathrm{AC}$ & BC & BD & DD & DF & $\mathbf{A}$ & B & D \\
\hline Tf/transferrin/ & 6 & 0.42 & - & 0.12 & - & - & 0.18 & 0.28 & 0.38 & - & 0.62 \\
\hline $\mathrm{Cp} /$ ceruloplasmin/ & 6 & 0.18 & - & - & 0.13 & 0.34 & 0.24 & 0.11 & 0.49 & 0.11 & 0.40 \\
\hline $\mathrm{Hb} /$ hemoglobin/ & 6 & 0.38 & 0.22 & 0.28 & - & 0.12 & - & - & 0.12 & 0.33 & 0.35 \\
\hline
\end{tabular}


Table 3. Genetic structure of multiparous goats per $\mathrm{La}, \mathrm{Lg}, \alpha \mathrm{S} 1-\mathrm{Cn}, \beta-\mathrm{Cn}$ loci*

\begin{tabular}{|c|c|c|c|c|c|c|c|c|c|c|c|c|}
\hline \multirow{3}{*}{ Locus } & \multirow{3}{*}{$\mathbf{n}$} & \multicolumn{9}{|c|}{ Frequency $P_{i}$} & \multirow{2}{*}{\multicolumn{2}{|c|}{ Degree of homozygosity }} \\
\hline & & \multicolumn{6}{|c|}{ Genotypes, \% } & \multicolumn{3}{|c|}{ Alleles } & & \\
\hline & & BC & BD & CD & $\mathbf{C F}$ & DD & DF & B & C & D & $\begin{array}{l}\text { According to } \alpha \mathrm{La}, \beta \mathrm{Lg}, \\
\alpha \mathrm{S} 1-\mathrm{Cn} \text { and } \beta-\mathrm{Cn} \text { loci }\end{array}$ & $\begin{array}{l}\text { According to } \\
\text { individual loci }\end{array}$ \\
\hline$\alpha$ Lactalbumin & 27 & 0.33 & 0.28 & - & 0.14 & - & 0.25 & 0.60 & 0.40 & - & \multirow{4}{*}{8} & 0 \\
\hline$\beta$ Lactoglobulin & 27 & 0.19 & - & 0.30 & 0.11 & 0.18 & 0.22 & 0.29 & 0.31 & 0.40 & & 20 \\
\hline$\alpha \mathrm{S} 1$ Casein & 27 & 0.40 & 0.21 & 0.11 & - & - & 0.28 & 0.63 & 0.11 & 0.26 & & 0 \\
\hline$\beta$ Casein & 27 & - & 0.20 & 0.20 & 0.22 & 0.15 & 0.23 & 0.22 & 0.48 & 0.30 & & 20 \\
\hline
\end{tabular}

Table 4. Genetic structure of Saanen goats per La, Lg, $\alpha \mathrm{S} 1-\mathrm{Cn}, \beta-\mathrm{Cn}$ loci*

\begin{tabular}{|c|c|c|c|c|c|c|c|c|c|c|}
\hline \multirow{3}{*}{ Locus } & \multirow{3}{*}{$\mathbf{n}$} & \multicolumn{9}{|c|}{ Frequency $P_{i}$} \\
\hline & & \multicolumn{6}{|c|}{ Genotypes, \% } & \multicolumn{3}{|c|}{ Alleles } \\
\hline & & $\mathbf{A A}$ & $\mathbf{A B}$ & $\mathrm{AC}$ & BB & BC & $\mathrm{CC}$ & $\mathbf{A}$ & B & D \\
\hline$\alpha$ lactalbumin & 6 & 0.29 & 0.36 & - & 0.35 & - & - & 0.38 & 0.62 & - \\
\hline$\beta$ lactoglobulin & 6 & 0.30 & 0.17 & 0.19 & 0.19 & 0.08 & 0.07 & 0.18 & 0.42 & 0.40 \\
\hline$\alpha \mathrm{S} 1$ casein & 6 & 0.27 & 0.14 & - & 0.11 & 0.45 & - & 0.33 & 0.41 & 0.26 \\
\hline$\beta$ casein & 6 & 0.48 & 0.26 & - & 0.08 & - & 0.18 & 0.21 & 0.49 & 0.30 \\
\hline
\end{tabular}

As to the D allele, it is manifested through one heterozygous genotype DF (0.28) in this locus. The homozygosity of $\alpha \mathrm{S} 1$ casein locus makes $0 \%$.

The locus $\beta$ casein ( $\beta-\mathrm{Cn})$ is also polymorphous; it is composed of B (0.22), C (0.48) and D (0.30) alleles. In this case the $\mathrm{B}$ allele comes forth through one genotype BD (0.20). Regarding the $\mathrm{C}$ allele, it has been manifested via two genotypes: $C D(0.20)$ and $C F(0.22)$. As to the $\mathrm{D}$ allele, it is remarkable, that it has formed 2 genotypes (DD homozygous and DF heterozygous genotypes), the occurrence rate of which has made 0.15 and 0.23 respectively. The homozygosity of the locus has made $20 \%$.

The homozygosity of multiparous goats per the investigated loci of the milk polymorphous proteins is equal to $8 \%$.

On the whole, the degree of homozygosity per the examined loci makes $22.5 \%$, which is most characteristic to the local crossbred goats.

Like in case of blood polymorphic proteins' investigations, in the above presented case, one regularity is clearly recorded, when comparing the study results with the similar indices of the Saanen goat breed, i.e., there is $100 \%$ matching in the numerical data of $\mathrm{D}$ allele in the milk polymorphic proteins (Table 4).

Evidently, the D allele of both blood and milk polymorphic proteins can be considered as a genetic marker from the multiparity perspective. Thus, the obtained data can be used during the genotyping assay of the local goats and as a test in the breeding process.

\section{Conclusion}

- The investigated loci of the blood serum and milk polymorphic proteins in the multiparous goats are polymorphic.

- The homozygosity degree has made $37 \%$ according to the polymorphous proteins of blood serum, while per the milk locus it makes $8 \%$.

- The data on occurrence rate of the D allele in the blood serum and milk polymorphous proteins for both the local and Saanen multiparous goats are absolutely similar, which can be considered as a genetic marker and used in the breeding procedure. 


\section{References}

1. Albenzio, M., Santillo, A., d'Angelo, F., Sevi A. (2009). Focusing on Casein Gene Cluster and Protein Profile in Garganica Goat Milk. J Dairy Res.; 76(1):83-9. doi: $10.1017 / \mathrm{S} 0022029908003853$.

2. Badalyan, M., Marmaryan, G., Marmaryan, Yu. (2018). Polymorphism of Blood Serum Protein-Transferrin, Ceruloplasmin, Albumin in Sheep of Karabakh Breed and the Relationship with the Natural Resistance Towards Epizootic Aphtae. Scientific Papers: Animal Science and Biotechnologies, 51 (1), - pp. 92-96.

3. Davydov, S.G. (1936). Selection of Farm Animals. - M.: Agricultural Publishing House, - 419 p. (in Russian).

4. Lotokov, K.M. (1935). Cattle Multiparity. - Animal Husbandry Problems, - V. 7, - pp. 63-100 (in Russian).

5. Merkureva, E.K., Abramova, Z.B., Bakay, A.V., Kochish, I.I. (1991). Genetics. M., Agropromizdat, 446 p. (in Russian).

6. Osterman, L.A. (1981). Methods for the Study of
Proteins and Nucleic Acids. Electrophoresis and Ultracentrifugation, Moscow - "Nauka", - 288 p. (in Russian).

7. Rout, P.K., Kumar, A., Mandal, A., Laloe, D., Singh, S.K., Roy, R. (2010). Characterization of Casein Gene Complex and Genetic Diversity Analysis in Indian Goats. Anim Biotechnol. 21(2):122-34. doi: 10.1080/10495390903534622.

8. Schagger, H., Jagow, von G. (1987). Tricine-Sodium Dodecyl Sulfate-Polyacrylamide Gel Electrophoresis for the Separation of Proteins in the Range from 1 to 100 kDa. // Anal. Biochem; - 166(2), - pp. 368-379.

9. Shen, W., Li, L., Pan, QJ., Qin, GQ., Geng, SM. (2004). Genetic Effect of the Marker Assisted Selection on Economic Traits of Goats. Yi Chuan. 26(5):625-30. Chinese.

10. Sulimova, GE., Abani Azari, M., Rostamzadeh, J., Mohammad Abani, MR, Lazebny̌̆, OE. (2007). Allelic Polymorphism of Kappa-Casein Gene (CSN3) in Russian Cattle Breeds and its Informative Value as a Genetic Marker. Genetika. 43(1):88-95 (in Russian). 